\title{
Identifying Strategies as a Ploy for Overcoming Negative Effects of COVIDization of Economy
}

Received: 31.08.2021

Available online: 28.12.2021

\section{Radko Radev*}

\begin{abstract}
The main goal of this publication is to highlight the importance of the strategy as a ploy to overcome the negative effects as a result of COVIDization of the economy. The term COVIDization of the economy is the term that best describes the situation caused by COVID-19 in the short term and the long term consequences it will have for the business. The first wave presented the companies the economic challenges that they had to deal with in the short term. The subsequent two new waves also determined the need for strategic changes on the part of companies. In these conditions, all five strategies derived by Mintzberg appear - plan, a pattern of behavior, positioning, ploy, perspective. The article substantiates from a theoretical point of view the importance of strategy as a ploy through some of the most popular concepts used in strategic management - McKinsey's 7S, the Pyramid for organizational development; through the Value-added chain, the Strategic map and Balance scorecard. Viewed in this way, "strategy" means the definition (undertaking) of a set of actions to achieve a specific goal under certain, set as a result of COVIDization, external conditions and available internal prerequisites.
\end{abstract}

The presented empirical data are the result of a study conducted in the period March-April, 2020.

Keywords: COVID-19, COVIDization, business strategies, strategic map, strategy as a ploy, strategic concepts, 7S, the Pyramid of organizational development

JEL: D04, D40, 121, 125

\section{INTRODUCTION}

Companies in Bulgaria and worldwide are not facing a crisis for the first time. However, for the first time in recent history, the health crisis has had such a complex impact on the PESTEL environment and the microenvironment of various industries globally and nationally. Given the unique situation in 2020, which finds its manifestation today, most company managers and owners did not have a clear idea of the nature of the situation, the extent and duration of the impact of processes unleashed by COVID 19. Here these processes are named with the term COVIDization. This term reflects the intial effects of COVID - 19 on companies' activities and the next waves. It also expresses longterm effects on society, the economy, specific economic sectors and strategic challenges facing individual companies.

\footnotetext{
* Department of Industrial Business, Business Faculty, University of National and World Economy
} 


\section{Articles}

This article aims to bring out strategy as a ploy taken by companies to overcome the harmful effects of the initial stage of COVIDization. The following tasks were set for implementing the main goal: first - to justify the need to accept the term COVIDization of the economy as relevant to the COVID situation; second - to expose the possibilities for choosing the strategy as a ploy for overcoming the harmful effects of COVIDization in short-term, based on the classical concept in strategic management; third - to present data from the survey, through which to illustrate the negative impact on the activities of companies; fourth - to outline the main actions taken by companies to overcome the situation. The article pays special attention to the negative influence of COVIDization on companies' activities and results. The cyclical nature of COVID-19, already expressed in three waves and anticipation of new ones, is evidence to the relevance of the subject area.

Many and different options for researching business strategies are possible. They can be studied based on the classification approach (Ansoff, 1965; Porter, 1980; 1985); by examining them from the point of view of the philosophy of different schools in strategic management (Mintzberg et al., 1998; Campbell et al., 2002); as an element of McKinsey's 7S management system (50MINUTES, 2015), the organizational development pyramid (Flamholtz and Randle, 1997); through the value-added chain (Porter, 1985), the Strategic map and Balance scorecard (Kaplan and Norton, 2001; 2003) and the organizationindustry relationship (Johnson et al., 2008; Porter, 1980). The possible manifestations of the strategies through which companies find an answer to the challenges posed by COVIDization are synthesized by Mintzber's 5Ps - strategy as a plan, a pattern of behavior,
Identifying Strategies as a Ploy for Overcoming

Negative Effects of COVIDization of Economy

positioning, ploy, perspective (Mintzberg et al., 2003). The derivation of these manifestations is conditioned by the different philosophies of the schools of strategic thought, suggesting different approaches to formulating and implementing strategies (Mintzberg et al., 1998; Campbell et al., 2002). These options cause several controversies when considering strategies: deliberateness vs. emergence, logic vs. creativity, revolution vs. evolution, responsiveness vs. synergy, competition vs. cooperation, compliance vs. choice. (De Wit and Meyer, 2010, pp.13-14) The COVIDization intensifies these contradictions. It is an emanation of the dynamically changing and uncertain environment. The increasing level of uncertainty resulting from COVIDization implies modifying the classical methods of strategic analysis implying enrichment of the traditional tools for analysis and decision-making (PESTEL analysis, Porter 5 Forces, Porter's Diamond) and using other tools: scenario planning, quantitative game theory, and options-pricing frame; qualitative game theory, latent demand analysis, and evolutionary models (Courtney et al., 1997, Coyne and Subramaniam, 1996).

The hypothesis proved here is that the strategy as a ploy is manifested in every company, regardless of its size and sectoral affiliation during the initial stage of COVIDization. The strategy as a ploy includes this set of activities through which companies seek to overcome the direct and indirect negative consequences of the initial stage of COVIDization of the economy.

The article presents the results of the data analysis obtained from an empirical study conducted by the Scientific and research center Innovation and Competitiveness, conducted in the period 10-30 April 2020. The survey topic is COVIDization of the 


\section{Articles}

economy: Consequences and Measures and covers 175 companies. The study examined the general condition before lockdown and the direct effect (negative and favorable impact) it had on companies from different sectors. It also identifies companies' actions to successfully overcome the negative impact and utilization of the positive ones. The companies' expectations regarding the impact of COVIDization were determined. The article emphasizes the results that represent the set of actions (strategy as a ploy) through which companies overcome the negative consequences in the short term. The other manifestations of the strategies derived by Mintzberg (as a plan, positioning, perspective, pattern of behavior) are not covered in this publication.

The results of the survey were presented at Bloomberg TV and Investor BG, as well as at conferences in the country and abroad. They were provided to the companies that took part in the study and to students from the University of National and World Economy in the bachelor's and master's degrees. The current publication is part of a series of publications dedicated to the COVIDization of the economy and business in Bulgaria. In this connection, additional researches have been conducted by the SRC Innovation and Competitiveness (U2B).

\section{Theoretical argumentation of the concept of COVIDization and derivation of the strategy as a ploy}

\subsection{COVIDization of the economy}

COVIDization of the economy is the term that best describes the situation caused by COVID -19 in the short term and the long-term consequences it will have for the business. COVIDization of the Economy catalyzes the realization of futuristic predictions to move from a homogeneous society based on the industrial revolution to a heterogeneous society inherent in the post-industrial (information) age. These changes are related to digitalization, the workplace, the family, the school and societies in general, knowledge-production, and information processing (Toffler, 1980). COVIDization of the economy leads to evolutionary and revolutionary changes in the company's business models, which are defined as karaoke and funky business (Nordström and Ridderstråle, 2002; 2004) without logo (Klein, 2009). At the heart of these changes are changing consumer behavior, increasing the importance of automation, digitalization, talent, individualism, and innovation. In the conditions of COVIDization of the economy, the shock of the future becomes a shock of the present, and only those companies that are prepared for it will have the opportunity to survive and develop. The rest will become part of the past. To be given this opportunity, companies need to deal with the challenges posed to them by COVIDization in the short term and the tidal COVID waves. The onset of the second and third waves in early 2021 confirmed the importance of this issue.

Numerous studies and publications on the impact of COVID-19 on the economy and business internationally confirm this view. A survey of 5700 SMEs identified the multifaceted impact that the COVID-19 lockdown in the United States has on their performance and economic performance; the expectations of the owners-managers, which vary widely, are studied; the expectations of the actions they take; the usefulness of the aid held (Bartik et al., 2020). The influence on the companies' export potential and the difficulties with the import of key resources 


\section{Articles}

are established (Minondo, 2021; Baldwin and Evenett (Eds), 2020; Hayakawa and Mukunok, 2021); accelerating automation and digitalization (Bloom and Prettner, 2020; Sarfraz et al., 2021), redefining the workplace and human resource management (Gigauri, 2020;), supply chain and value-added (Agrawal et al., 2020; Zeshan, 2020; Alkahtani et al., 2021; Hayakawa and Mukunok, 2021), change in the social responsibility of business (He and Harris, 2020). This thematic scope of research is not exhaustive. However, it is evidence of the need to identify areas of change in the business model of companies by successfully adapting to changing conditions or making strategic changes. (Fitriasarin, 2021; Seetharaman, 2020). COVIDization of the Economy determines the direction and strength of the influence of PESTEL factors and the changes that are observed in the five Michael Porter's forces in the individual sectors, subsectors and groups of economic activities. This influence is formed in the conditions in which the world, societies, economies, individual sectors, and companies have started/advanced/carried out their transformation to the transition to automation, digitalization, green (circular) economy. The COVIDization of the Economy challenges companies to take action to address the effects in the short term without losing focus on providing conditions for sustainable development in the medium and long term. The starting point for taking one or another action is to determine the company's strategic position and direction and strength of influence of COVIDization of the economy.

\subsection{Defining the strategy as a ploy}

The derivation of strategy as a ploy during the first stage of COVIDization of the economy is based on Mintzberg's five Ps - strategy
Identifying Strategies as a Ploy for Overcoming

Negative Effects of COVIDization of Economy

as a plan, positioning, pattern of behavior, perspectives, and ploy. (Mintzberg et al., 2003) They are referred to different schools of strategic thoughts (Mintzberg et al., 1998). Strategy as a ploy considers taking maneuvers to gain an advantage against competitors in a specific external environment (Mintzberg, 1987). At first glance, the strategy as a ploy is close in meaning to understanding tactics. However, there is a fundamental difference between them. Tactics emanates from the strategy as a specific approach to achieving the main goal. Thus tactics are components of strategy, through which the strategy is developed into specific mechanisms and actions. Strategy as a ploy is short-term in nature and involves achieving a specific goal under certain external conditions and internal prerequisites (set as a result of COVIDization of the economy). Viewed in this way, "strategy" means the formulation (undertaking) of a set of actions to solve a specific problem (initial effects of COVIDization). Here are examined this set of activities through which the company overcomes the negative effects caused by the COVID-19 first wave.

The environmental conditions conditioned by the COVIDization require finding solutions to specific problems that have arisen. Strategy as a ploy does not dismiss the need to consider strategy as a plan, positioning, pattern of behavior, and perspective. On the contrary - it complements it. Viewed in this way, strategy as a ploy is not only maneuvers against competitors. It also means undertaking certain moves to solve specific problems (overcome specific situations) caused by the COVIDization of the economy. COVIDization also requires companies to rethink their development in the medium and long term. Thus an active management approach requires managers to find an adequate 


\section{Articles}

approach (strategy as a ploy) for overcoming short-term problems without losing focus on future development.

\subsection{Strategy as a ploy in the context of classical models in strategic management}

The McKinsey Model 7S allows to establish the current configuration to ensure organizational efficiency. Together with the system and the structure, the strategy is considered hard elements, and shared values/subordinated goals, employees, style, abilities (skills) as soft (50MINUTES, 2015). According to the model's logic, its elements reflect the achieved configuration in the company and have a long-term character. The elements of organizational efficiency determine the capacity of the organization to meet the challenges that companies face during the COVIDization of the economy. The possibilities for solutions (strategy as a ploy) for overcoming the adverse effects in the short-run focus on the functional strategies and the staff. McKinsey's 7S is a key tool for transformation in the medium and long term due to the impact of COVIDization.

The Pyramid of organizational development gives another perspective for deriving strategies as a ploy (Flamholtz and Randle, 1997). An established competitive strategy, the business concept, and strategic mission form the business's foundation. In this sense, strategy is considered one of the fundamental elements of organizational development. Six more levels are built on the business's foundation, defined as tasks for organizational development: markets and products (services) supplied; resource management; operational system; corporate culture. This model helps to establish the company's state (strategic position, stage of development) at the onset of COVIDization and future expectations.
On this basis, the actions through which companies can overcome the harmful effects of COVIDization are derived. In the medium and long term, changes may affect generic competitive strategies as a vital element of the company's business model and the company's mission and corporate culture at the top of the pyramid. In the short term, the possible solutions, representing the strategy as a ploy, are hidden in two elements - resources management and operation system. In the medium term, the importance of product and market strategies is manifested.

The "Value-added chain" model reveals the content of the competitive business strategy (Porter, 1985). The basis of its definition is the identification of competitive positioning adequate to the external conditions and internal prerequisites (Porter, 1980). Realization in the competitive business strategy is carried out through coordination of the functional strategies and policies. They are the basis for the formation of sustainable competitive advantages. The benefit of the value-added chain model in the short run (in the manifestation of the strategy as a ploy) is that it helps identify areas where costs can be reduced without compromising consumer value. It is also possible to identify activities to add value to consumers in the context of COVIDization to respond to changes in consumer behavior, taking into account costs. In the long run, the companies should rethink the cost-benefit ratio for consumers - profit margin.

The starting point for deciding on the choice of approach to find an answer to address the effects of COVIDization are the elements of the company business model. The business model contains answers to the following questions:1) Who are the company's target customers? 2) What is the value proposition to customers 


\section{Articles}

(product and services)? 3) How is this value to be delivered (The value chain) - processes and activities. 4) How does the company/business generate profit (financial model) and produce value for our shareholders and stakeholders? (Gassmann et al., 2014) The first question concerns business strategy formulation by defining the strategic business sphere and product-market strategies based on Ansoff's matrix (Ansoff, 1965). The second concerns the choice of competitive strategies and competitive advantages proposed by Porter (1985). The answer to the third question is related to the choice of a value chain through a system of primary and secondary corporate processes, building an organization system for effective management and organizational development. The fourth element reveals the company's financial model based on the decisions made regarding the other elements of the business model. The adverse impact of COVIDization affects all aspects of the model, which is reflected in the financial results. In the short run, the compensatory mechanisms of the strategy as a ploy are hidden in the third element. In the medium and long term, COVIDization can cause changes in all elements of the business model. When the change takes place in more than one of the elements, there is a strategic change (Gassmann et al., 2014).

An important issue related to business strategies is the relationship internal environment - external environment, as a result of which two approaches to decision making are possible - Industry / Organization or Organization / Industry (Johnson et al., 2008; Volberda et al., 2011; Prohland and Hamel, 1990). Both approaches should be used in defining a strategy as a ploy to overcome the negative effects of COVIDization. In the short run, they are used to assess the impact of
Identifying Strategies as a Ploy for Overcoming

Negative Effects of COVIDization of Economy

environmental factors and determine actions (strategy as a ploy) to overcome the emergency problems. Based on the relationship „internalexternal environment," it is possible to derive several methodological approaches: «macromicro - internal company environment»; "micromacro - internal company environment," «internal company environment - micro-macro." The combination of these approaches makes it possible to look for different solutions in the combined consideration of the above concepts of strategic management.

\subsection{Strategy as a ploy from the point of view of the strategic business map}

In order to present the strategy as a ploy, it is important to consider it in the context of a strategic business map and a balanced scorecard (BSC). They reveal the content of the strategy and the other elements of the concepts of strategic management discussed above (Kaplan and Norton, 2001; 2003). The strategic business map and the BSC detail the strategy in four critical areas: 1) the financial perspective (income, expenses, profit, value for shareholders); 2) customers (customer value proposition); 3) internal processes - topics related to core, market, innovation, and regulatory activities; 4) in terms of opportunities for development and growth based on intangible assets owned by the organization (human capital, information capital, organization capital) (Kaplan and Norton, 2001; 2003).

According to the strategic map and BSC, the financial ratios result from efficiency (sustainable customer satisfaction by providing the value they are looking for) and efficiency (productivity of the four internal topics implemented). The effects of undertaking changes in internal processes are manifested in different time intervals. Improving internal 


\section{Articles}

processes leads to cost savings and to improving the quality of products and services offered in the short term. They are used in defining strategies as a ploy to overcome the adverse effects of COVIAization in the short term. Within one to two years, the effects of a change in market activity appear after the initial improvement of the customer relationship. Increasing revenues and costs due to innovation processes take more time (Kaplan and Norten, 2003).

Balancing these elements allows companies to overcome the negative effects of COVIDization of the economy in the shortterm and long-term challenges. It is thus that the contradiction will be resolved between investing in opportunities for development and growth based on intangible assets owned by the organization (human capital, information capital, organization capital) and overcome problems (e.g. reducing costs to improve financial results) in the short term. This contradiction is exacerbated in the context of the COVIDization of the economy. The dominant objective for creating sustained growth in shareholder value must be traded off for surviving in the short term, especially when the influence of COVIDization is highly unfavorable. (Kaplan and Norten, 2003)

\section{COVIDization of the economy and manifestations of strategy as a ploy}

The decision to overcome the challenges posed by COVIDization is based on schools of strategic thinking (Mintzberg et al., 1998; Campbell et al., 2002). They are reflected in the five manifestations of the strategy derived by Mintzberg. A strategy such as a plan and positioning are inherent in formalized schools the design school, the school of strategic planning and positioning. The manifestations of the strategy as a pattern of behavior and perspective are represented by the informal schools: entrepreneurial and cognitive school, learning schools, power school, and school of organizational culture. The configuration school includes the manifestation of all types of strategies, as it combines the advantages of all schools, taking into account the specifics of the company and the conditions of the external environment. (Mintzberg et al., 1998)

At the onset of the first wave, none of the four manifestations mentioned were relevant to the situation due to the surprising measures introduced globally and nationally. In this context, the importance of the strategy as a ploy (planned or not) for overcoming the negative effects became apparent. In addition to finding a solution in the short term, the second and third waves required companies to assess their strategic compliance with the circumstances changed as a result of COVIDization. Thus, the definition of the strategy as a ploy for overcoming the negative effects of COVIDization is combined with the other manifestations of the strategy. In the short and medium-term, this means preparing a crisis plan and alternative development plans, and in the medium and long term, a change in positioning, behavior pattern, and perspective.

\subsection{Research methodology}

The survey was conducted in April 2020. It covered 175 companies from different sectors of the economy. The study targeted managers and owners of companies in Bulgaria. The objectives of the study are: to study the impact of COVID -19 on companies in Bulgaria; to evaluate the measures proposed by the state and the banks; to establish the actions that companies take, as well as to determine their expectations in the future. The survey was structured in four sections. 


\section{Articles}

The first section collects information on 1) the main characteristics of the company - the value of income, the value of assets, number of employees; 2) the priority targets for 2020 before the start of COVIDization; 3 ) information on the financial position - profitability of income, solvency, liquidity.

The second section examines the impact of COVIDization: 1) a summary impact assessment; 2) influence on the revenues and profits of the company; 3 ) on the company's receivables, increase in inventories, ability to meet obligations and deliveries of important materials.

The third section identifies the set of actions that form the manifestation of the strategy as a ploy to overcome the initial negative effects of COVIDization of the economy: 1) actions related to costs, including wage costs, marketing, and sales; administrative costs, training costs, and social benefits; 2) the used opportunities from bank crediting; 3) measures related to human resources; 4) attitude to the measures proposed by the state; 4) market actions.

The fourth section allows to gather information about the companies: 1) the expectations and attitudes regarding the duration and the degree of influence of COVIDization of the economy on the sector and the company business; 2) the intentions for adaptation and strategic change that the companies intend to undertake in the short and long term.

The main research tool used to achieve the goal of the study is the questionnaire. It consists of a set of questions in which respondents choose/write their own answers: multiple-choice questions, rating scale questions, Likert scale questions, matrix
Identifying Strategies as a Ploy for Overcoming

Negative Effects of COVIDization of Economy

questions, dropdown questions. The way the study was conducted did not allow to gather the information allowing correlation and regression analyses. The results of the analysis are processed by descriptive statistics and visualized by graphs and charts.

\subsection{Results of the empirical study}

COVIDization found some companies prepared for what was happening, in a good starting strategic position and financial condition. Others turned out to be completely unprepared - with an unfavorable strategic position and financial health.

\subsubsection{Negative manifestations at the initial stage of COVIDization}

The primary negative influence of the initial stage of COVIDization is the decline in revenues. In the case of the unfavorable and favorable impact, three degrees are determined: extremely unfavorable, when due to the undertaken measures, the company temporarily suspends its activity; very unfavorable when due to the measures taken a decrease in revenues of more than $50 \%$ are registered; unfavorable when the decline in revenue is $20-50 \%$; unfavorable, but surmountable when revenues fall up to $20 \%$. The total share of companies in which the impact is unfavorable in one of the four degrees amounts to 76\%: the final degree of adverse effect is formed at $10 \%$; solid negative impact is present in $34 \%$ of the companies participating in the survey; in $23 \%$ of the companies the situation is defined as unfavorable, but surmountable. The companies in which the influence is a neutral amount to $16 \%$. In the other companies the influence is defined as favorable. (Figure 1) 
Articles

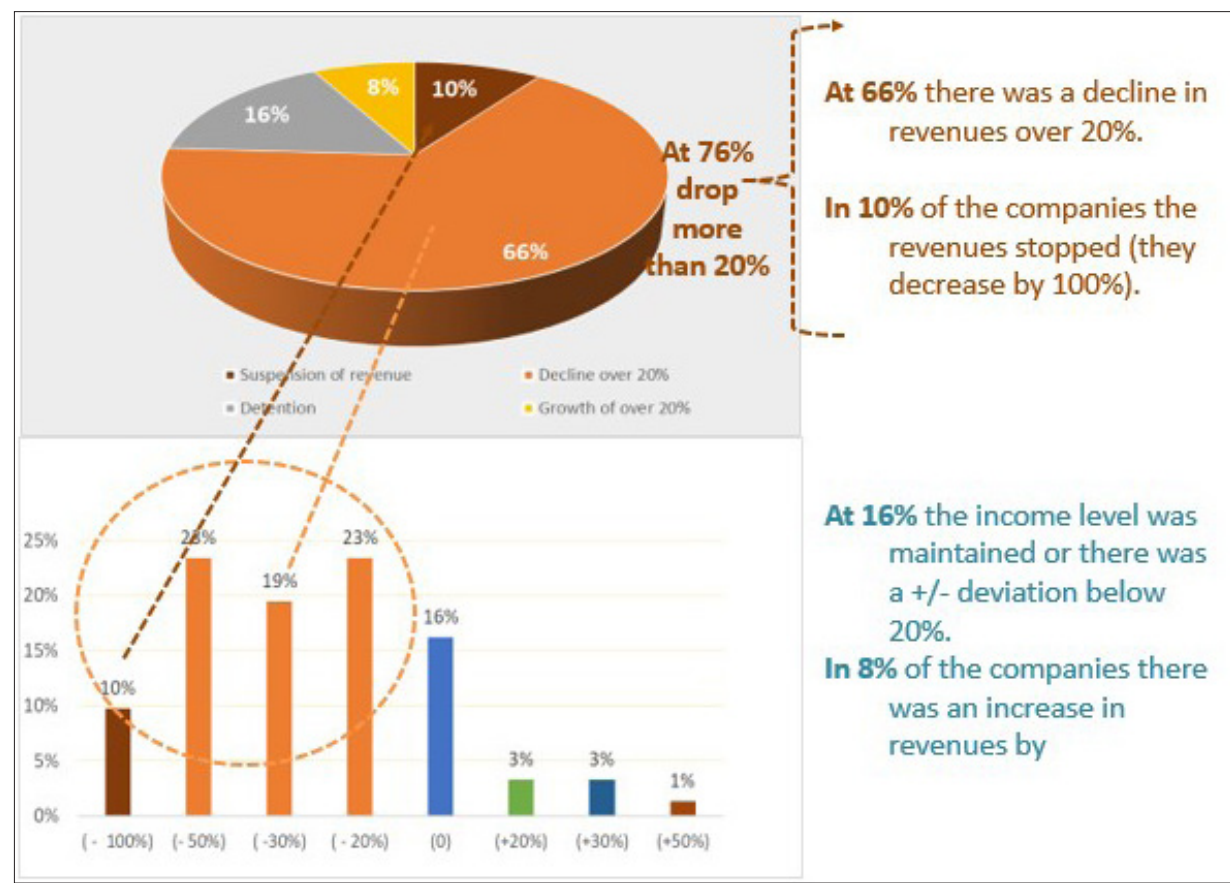

Figure 1: Impact of COVIdization on companies' revenues

In addition to the impact on revenue, the difficulties with service, difficulties in initial stage of COVIDization was manifested in some other adverse effects: inability to collect receivables, increased liabilities, (Figure 2)

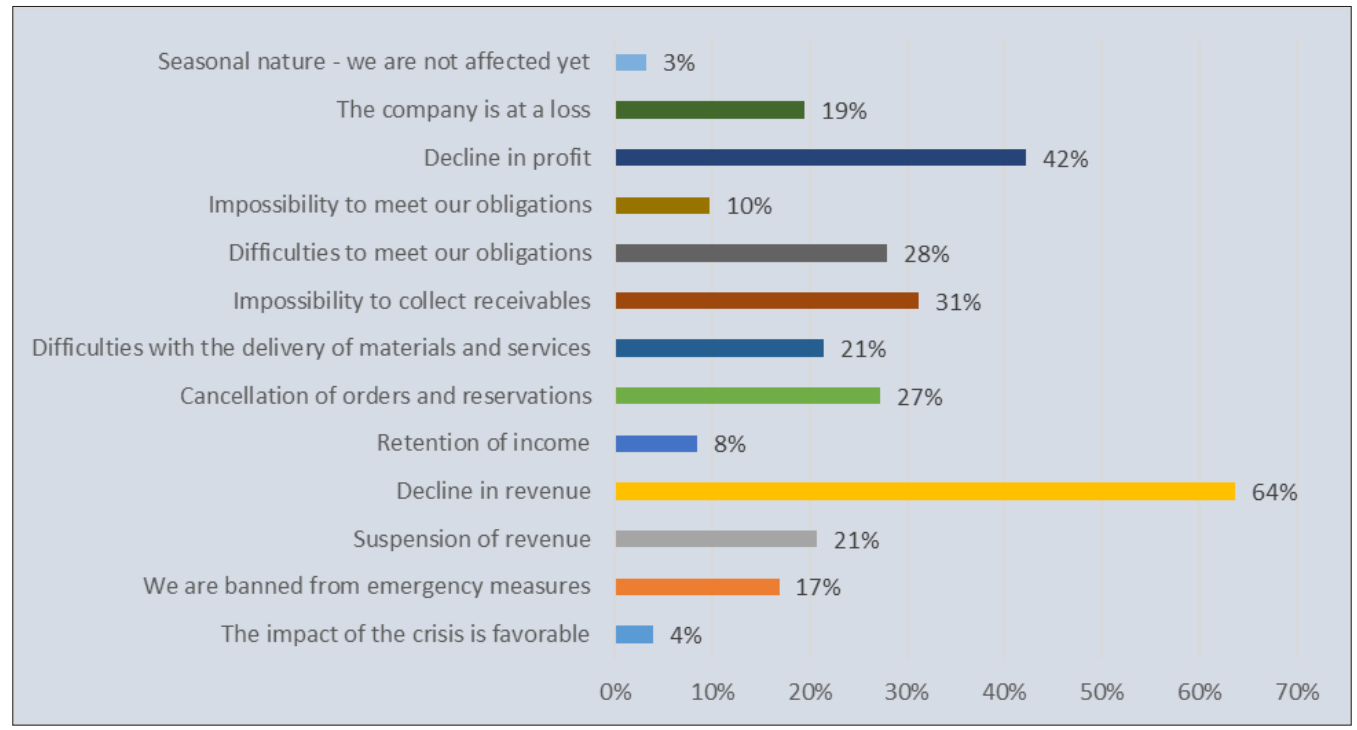

Figure 2: Negative effects of COVIDization on companies' activity 


\section{Articles}

All these unfavorable circumstances required immediate decisions. These decisions took the form of a set of concrete activities that are the manifestation of the strategy as a ploy to overcome them. Undertaking the strategy as a ploy (set of activities) is based on the company's strategic position before the state of emergency. The strategic position determined the company's internal circumstances to overcome external threats or exploid opportunities caused by COVIDization.

\subsubsection{Manifestation of the strategy as a ploy to overcome the negative effects of COVIDization}

Given the situation and the multifaceted impact of the initial stage of COVIDization, companies had to determine a set of actions
Identifying Strategies as a Ploy for Overcoming

Negative Effects of COVIDization of Economy

to overcome the negative consequences. As a result of the interviews, several main groups of measures were identified to overcome the negative consequences. The first group of actions concerns cost reductions. The most serious is the reduction of administrative costs $(57 \%)$, followed by the costs of trade and marketing (36\%) and social benefits (25\%). The other main group of measures to overcome the negative consequences is related to staff. $45 \%$ of the companies undertook to put staff on leave, $25 \%$ - reduction of training costs and $15 \%$ reduction of salaries. The third group refers to the actions of companies with banks. The highest percentage of this group of measures is the renegotiation of the terms of already concluded loans (14\%). The others are short-term loans $(11 \%)$, overdrafts $(12 \%)$ and long-term loans (7\%) (Figure 3).

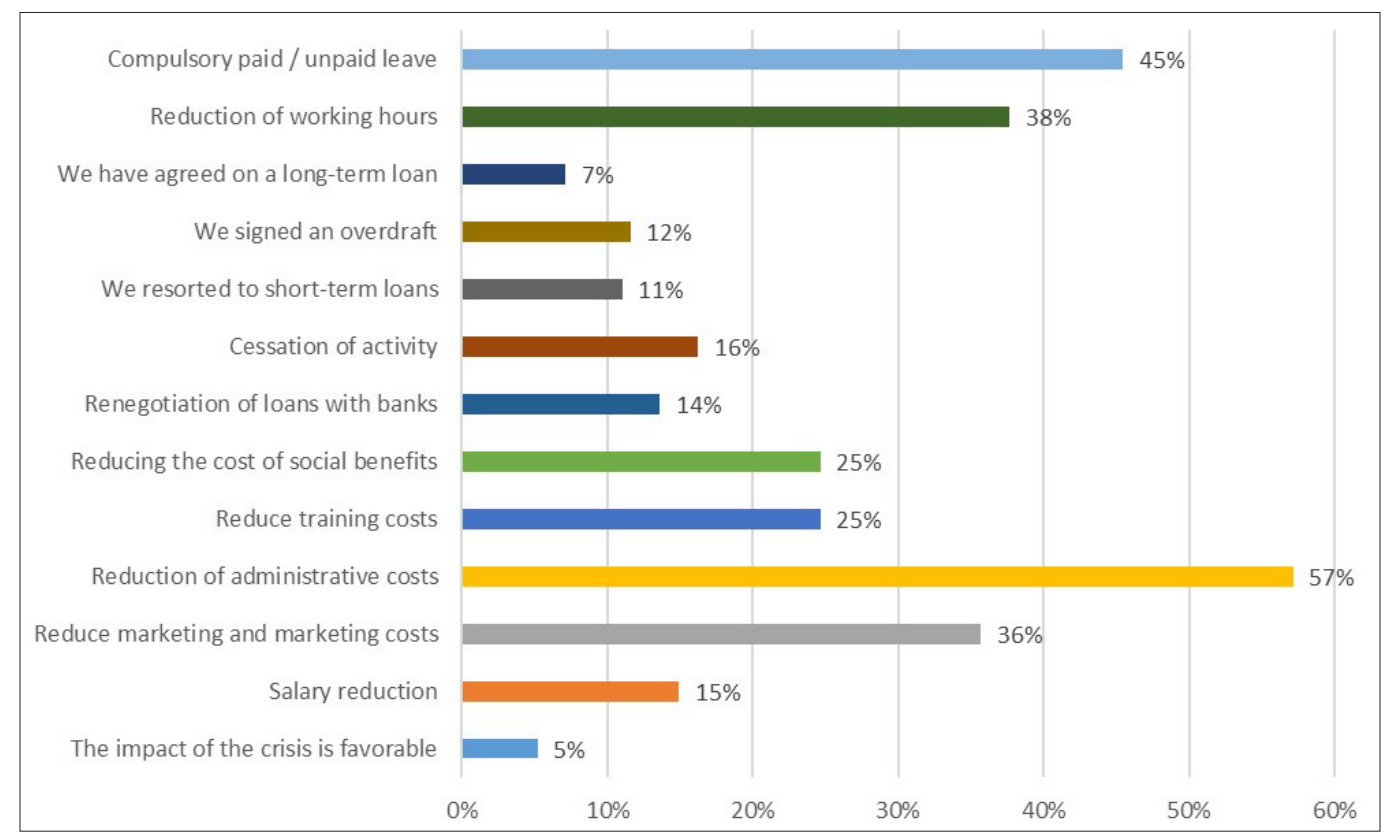

Figure 3: Set of activities (strategy as a ploy) for overcoming the negative effects caused by COVIDization 


\section{Articles}

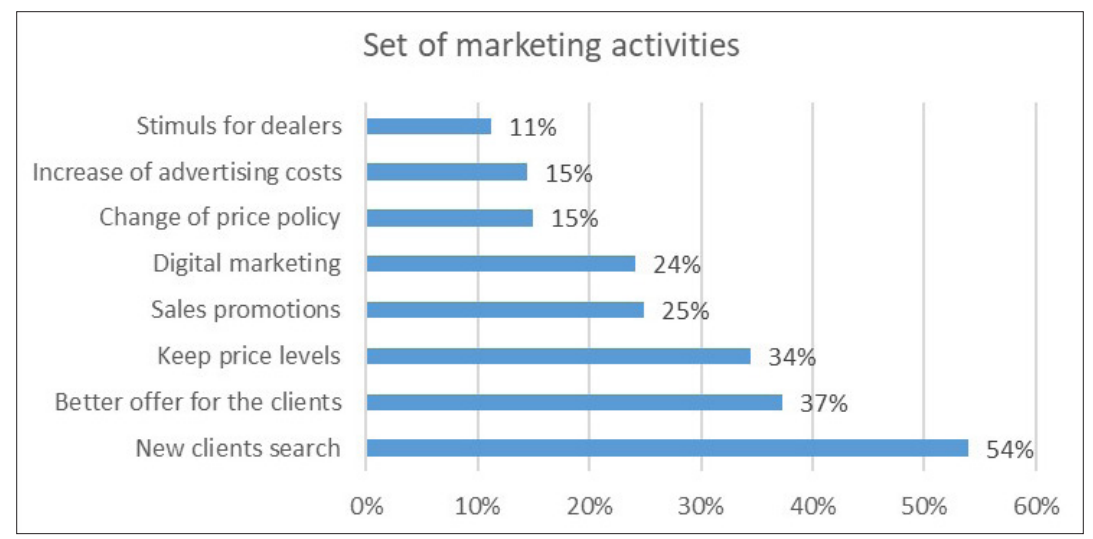

Figure 4: Set of marketing activities (strategy as a ploy) for overcoming the negative effects caused by COVIDization

Together with restrictive measures, some companies have undertaken a market set of activities. The short-term activity that companies attach the greatest importance to is searching for new customers (54\%). That means that companies are looking for options to compensate for the decline in revenue with their existing products. The next important market activity is the revision of offers to existing customers (37\%). $34 \%$ of companies kept their prices. The promotions and benefits of digital marketing are also essential activities. (Figure 4)
The study coincided in time with the support measures proposed by the Bulgarian government. The presented data indicate that the majority of companies did not envisage using these measures as an element of their strategy as a ploy (set of activities). The biggest part claimed they could not meet the requirements $(47 \%)$ or regarded them as inadequate $(27 \%)$. Only $20 \%$ of the companies stated they would take advantage of the measures proposed to overcome the crisis (Figure 5).

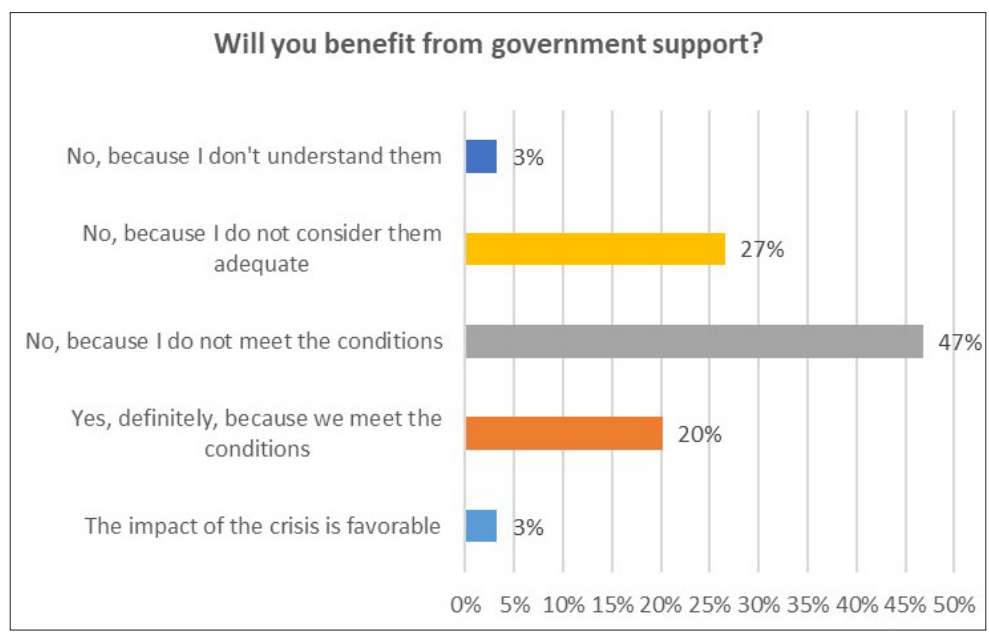

Figure 5: Perception of the measures proposed by the government support 


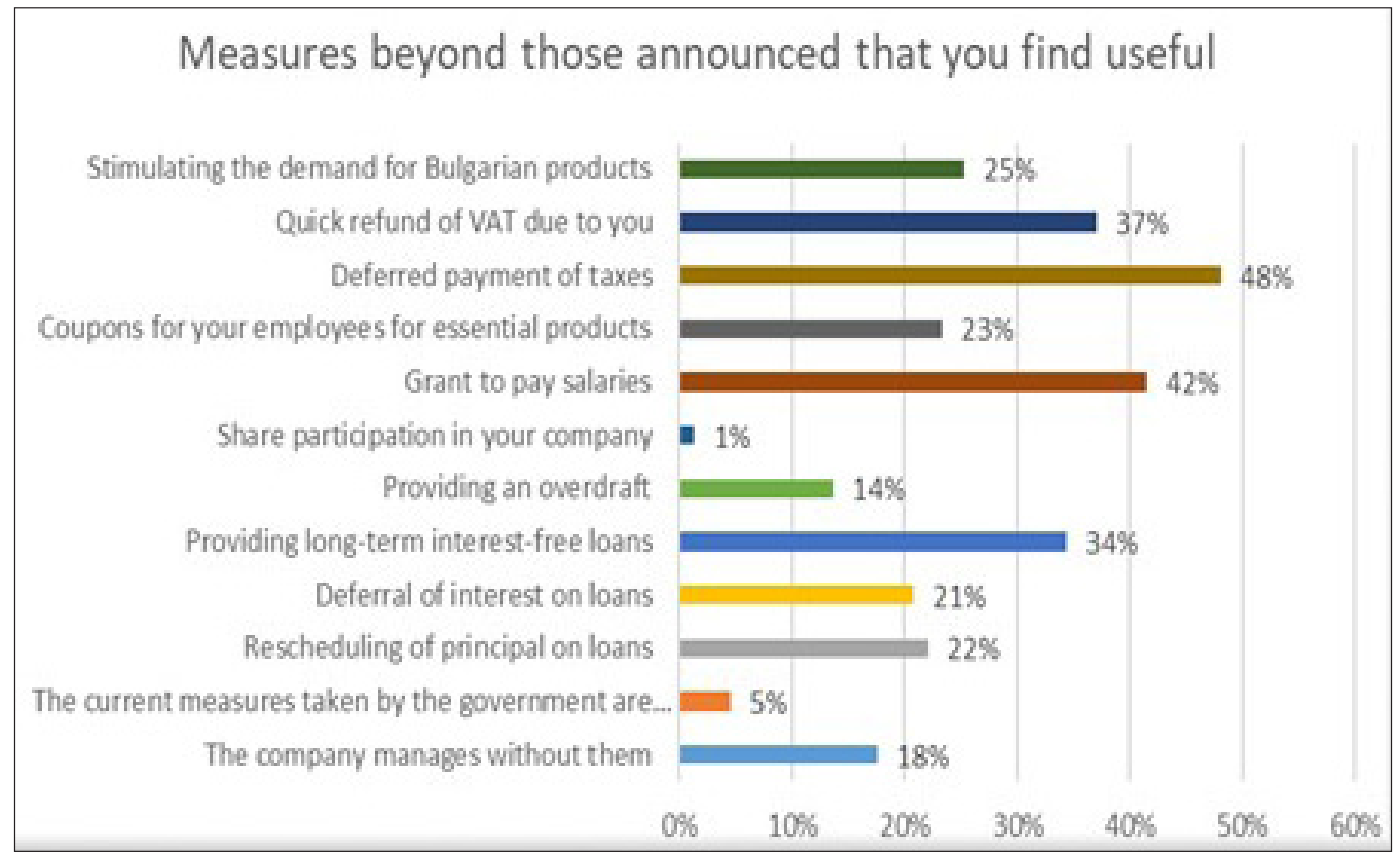

Figure 6: Alternative measures proposed by the companies

Based on their strategic position and the specific impact of COVID-19 on their business, the companies identified several additional measures they saw as far more helpful (Figure 6). These measures were not foreseen in the initial government package. Some of the measures were proposed by the government afterwards. This is proof that the business knew better the needs for overcoming the negative influence of COVIDization.

\subsection{Main findings}

By definition, undertaking the strategy as a ploy should be based on a complete understanding of the company's strategic position and direction and the extent of the impact of COVIDization on the economy. Based on this understanding, two general situations were derived.

The first situation appeared when the business was closed or the negative impact was strongly negative. When a business is analyzed that was"closed" due to the first wave of COVIDization, there was a complete cessation of revenue. This extremely negative effect decreases proportionally with a decrease in the rate of decline in revenue. If they meet the conditions, companies with a revenue decline of more than $20 \%$ took mainly cost-cutting activities staff, bank loans, and government assistance. In the case of negative influence, success was determined by the degree of influence and the company's strategic position. If the company's strategic position was favorable, the success of the undertaken strategy as a ploy was higher. In the case of an unfavorable strategic position, combined with a negative impact of COVIDization, the negative effects for the company were much more intense compared to the first group. The companies with unfavorable positions were much more endangered for their survival, despite the set of activities taken. Their survival was 


\section{Articles}

dependent on the timely and appropriate state support.

Under the second situation when the business was positively influenced, unforeseen opportunities to increase revenue were identified. To take advantage of these opportunities that COVIDization opens up companies needed appropriate marketing activities and rapid expansion of their capacity. If there were an unfavorable strategic position and a favorable impact on COVIDization, companies were unable to "absorb" the positive effects of COVIDization. In cases where the positive impact is combined with a favorable strategic position, the strategy as a ploy included the set of activities for maximizing this positive effect.

These two basic situations were derived, as the uniqueness of the situation caused by COVIDization of the economy was taken into account. The set of activities undertaken at the initial stage were determined by the lack of complete understanding of the extent of the impact of external factors caused by the first COVID-19 wave.

\section{Conclusion}

Influenced by the crisis, all types of companies undertook a set of activities (strategy as a ploy), through which they tried to overcome the negative impact of COVIDization on the economy or to maximize the positive one. COVIDization of the economy as a term describes the situation caused by COVID -19 in the short term and the long-term consequences it will have for the business with the onset of the next waves. The article has highlighted the importance of strategies as a ploy to overcome the short-term negative effects caused by the first wave of COVID-19. Based on classical concepts in strategic management, the possibilities for choosing the strategy as a ploy were identified. The study confirmed the hypothesis that during the first wave of COVIDization, the strategy as a ploy was manifested in every company, regardless of its size and sectoral affiliation. As a result of the sharp drop in revenue, strategy as a ploy takes the form of a set of activities related to reducing costs, temporary or permanent staff reductions, bank loans and marketing activities. The COVIDization also forced companies to rethink their mediumand long-term development and take strategic moves. These decisions will be presented in other publications.

\section{References}

Agrawal, S., Jamwal, A. and Gupta, S. (2020) Effect of COVID-19 on the Indian Economy and Supply Chain. Preprints. [Online] Available: $\quad$ https://www.preprints.org/ manuscript/202005.0148/v1 [Accessed May 2021]

Alkahtani, M., Omair, M., Khalid, Q. S., Hussain, G., Ahmad, I., Pruncu, C. (2021) A COVID-19 Supply Chain Management Strategy Based on Variable Production under Uncertain Environment Conditions. Int. J. Environ. Res. Public Health. [Online] 18 (4):1662, Available: https://doi.org/10.3390/ ijerph18041662 [Accessed May 2021]

Ansoff, I., 1965. Corporate strategy: an analytic approach to business policy for growth and expansion. 1-th Edition. McGrawHill.

Baldwin, R. and Evenett, S. J. (Rds), 2020. COVID-19 and Trade Policy: Why Turning Inward Won't Work. CEPR Press.

Bartik, A., Bertrand, M., Cullen, Z.B., Glaeser, E.L., Luca, M. and Stanton, C. (2020) The Impact of COVID-19 on Small Business Outcomes and Expectations. Proceedings of the National Academy of Sciences. [Online] 


\section{Articles}

117 (30) Available: https://doi.org/10.1073/ pnas.2006991117 [Accessed May 2021]

Bloom, D., Prettner., K., (2020) The macroeconomic Effects Of Automation And The Role Of COVID-19 in reinforcing their dynamics. VOXeu. [Online] Available: https://voxeu.org/article/covid-19-andmacroeconomic-effects-automation [Accessed April 2021]

Campbell, D., Stonehouse, G., Houston, B., 2002. Business Strategy: an introduction. 2-th Edition. Oxford: Butterworth Heinemann publication. pp. 15-18.

Courtney, H., Kirkland, J., and Viguerie, P. (1997) Strategy Under Uncertainty. Harvard Business Review. [Online] Available: https:// hbr.org/1997/11/strategy-under-uncertainty [Accessed May 2021]

Coyne, K. P., Subramaniam, S. (1996) Bringing Discipline To Strategy. McKinsey Quarterly, 00475394, Issue 4. [Online] Available: https:// www.proquest.com/docview/224546465?pqorigsite=gscholar \&fromopenview $=$ true [Accessed May 2021]

De Wit, B., Meyer, R., 2010. Strategy: Process, Content, Context: an International Perspective. 4-th edition. Cengage Learning, EMEA.

Fitriasarin, F. (2020) How do Small and Medium Enterprise (SME) survive the COVID-19 outbreak?. Jurnal Inovasi Ekonomi. Special Issue of Economic Challenges in COVID-19 Outbreak. [Online] 5 (2) pp. 53-62. Available: http://202.52.52.22/index.php/JIKO/ article/view/11838 [Accessed May 2021]

50MINUTES. 2015, McKinsey 7S Framework: Boost business performance, prepare for change and implement effective strategies.

Flamholtz, E. G., Randle, Y. 1997. Growing Pains: Transitioning from an Entrepreneurship to a Professionally Managed Firm. BerrettKoehler Publishers. pp. 25-47.
Identifying Strategies as a Ploy for Overcoming

Negative Effects of COVIDization of Economy

Gassmann, O., Frankenberger, K., Csik, M., 2014. The Business Model Navigator: 55 Models That Will Revolutionise Your Business.

Gigauri, I. (2020) Influence of Covid-19 Crisis on Human Resource Management and Companies' Response: The Expert Study. International Journal of Management Science and Business Administration, Inovatus Services Ltd., [Online] vol. 6(6), pp. 1524 Available: http://dx.doi.org/10.18775/ ijmsba.1849-5664-5419.2014.66.1002 [Accessed May 2021]

Hayakawa, K. and Mukunok, H. 2021. Impacts of COVID-19 on Global Value Chains. The Development Economic. Institute of Developing Economies. [Online] Available: https://doi. org/10.1111/deve.12275 [Accessed May 2021]

He, H., \& Harris, L.,2020. The impact of Covid-19 pandemic on corporate social responsibility and marketing philosophy. Journal of business research, 116, pp.176-182. https://doi.org/10.1016/j.jbusres.2020.05.030

Johnson, G., Scholes, K., Whittington,R., 2008. Exploring Corporate Strategy.

Kaplan, B.S., Norton, D. P., 2001. Strategic Focused Organizations: How Balanced Scorecard Companies Thrive in the New Business. Harvard Business Review Press.

Kaplan, B.S., Norton, D.P., 2003. Strategic maps. Converting Intangible Assets into Tangible Outcomes. Harvard Business School Publishing

Klein, N., 2009. No Logo: No Space, No Choice, No Jobs. Picador.

Minondo, A., 2021. Impact of COVID-19 on the trade of goods and services in Spain, Applied Economic Analysis, [Online] 29 (85), pp. 5876. Available: https://doi.org/10.1108/AEA-112020-0156 [Accessed May 2021]

Mintzberg, H., Ahlstrand, B., Lampel, J., 1998. Strategy Safari: A Guided Tour Through The Wilds of Strategic Mangament. New York: Free Pess. 


\section{Articles}

Mintzberg, H., Lamel, J., Quinn, J. Ghoshal, S., 2003. The Strategy Process: concepts, contexts, cases. 2-th Euoropeon edition, Piorson, pp. 2-9.

Mintzberg H., 1987. The Strategy Concept I: Five Ps for Strategy. California Management Review. 30(1): pp. 11-24. doi:10.2307/41165263 [Accessed May 2021]

Nordström,K., Ridderstråle, J., 2002. Funky Business: Talent Makes Capital Dance. Pearson Education.

Nordström,K., Ridderstråle, J., 2004. Karaoke Capitalism: Management for Mankind. Pearson Education.

Porter, M., 1980. Competitive Strategy: Techniques for Analyzing Industries and Competitors. New York: Free Press. pp. 300324.

Porter, M., 1985. Competitive Advantage: Creating and sustaining superior perfomance. New York: Free Press, pp. 62-164; 445-513.; 164-201; 33-62.

Prohland, C. K. and Hamel, G. 1990. The Core Competence of the Corporation. In: Harvard Business Review, 68 (3), pp. 79-91. [Online] Available: https://hbr.org/1990/05/the-core- competence-of-the-corporation [Accessed July 2020]

Sarfraz, Z., Sarfraz, A., Iftikar, H. M. and Akhund, R., (2021). Is COVID-19 pushing us to the Fifth Industrial Revolution (Society 5.0)?, Pakistan journal of medical sciences, [Online] 37(2), pp. 591-594. Available: https://doi. org/10.12669/pjms.37.2.3387 [Accessed May 2021]

Seetharaman, P. (2020) Business models shifts: Impact of Covid-19. International Journal of Information Management, [Online] 54. Available: https://doi.org/10.1016/j. ijinfomgt.2020.102173 [Accessed May 2021]

Toffler, A., 1980. The Third Wave. First edition. William Morrow (US).

Volberda, H.W., Morgan, R., Hitt, M. A., Ireland, R. D., Reinmoeller, P., 2011. Strategic Management: Competitiveness and Globalization: Concepts and Cases. SouthWestern Cengage Learning, pp. 93-121.

Zeshan, M. (2020) Double-hit scenario of Covid-19 and global value chains. Environ Dev Sustain. [Online] Available: https://doi. org/10.1007/s10668-020-00982-w [Accessed May 2021] 